\title{
CRISE E REESTRUTURAÇÃO DE UMA ESTATAL FINAN- CEIRA: \\ O BANCO DO BRASIL, DO CRUZADO AO REAL
}

\author{
Carlos Augusto Vidotto*
}

\section{INTRODUÇÃO}

A desarticulação dos fatores internos que dinamizaram a economia brasileira nos anos setenta e a reversão do quadro de elevada liquidez internacional, ocorrida no início da década seguinte, integram os principais vetores que, convergentes num primeiro momento para a deterioração fiscal e financeira do setor público, desdobraram-se a seguir em outras consequiências críticas amplamente conhecidas. Aspecto relevante das transformações estruturais da sociedade brasileira ao longo dessa trajetória, o caráter da relação entre Estado e economia também experimentou significativa modificação, particularmente no que se refere às condições financeiras diferenciadas que promoveram a acumulação de capital em setores priorizados pela política econômica.

Considerando tal panorama, este artigo aborda a estatal financeira Banco do Brasil (BB) na contraditória condição de agente de políticas de fomento creditício e simultaneamente portador de exigências particulares de valorização. Seu foco limita-se a uma etapa singular na história da instituição, que se estende aproximadamente de 1986, quando o BB deixou de ser autoridade monetária e caixa do Tesouro, até 1996, quando o Tesouro Nacional contribuiu para o aporte de $\mathrm{R} \$ 8$ bilhões destinado a sua capitalização. Um exame mais detido de períodos anteriores encontra-se em outros trabalhos (VIDOTTO, 1995 e 1997).

A natureza específica do objeto, uma empresa estatal inserida nos mercados financeiros, requer uma menção ainda que breve ao marco conceitual que informa a problematização de sua dinâmica . Como qualquer empresa estatal,

* Mestre e doutorando em Economia pelo IE-Unicamp. 
seu movimento de expansão e eventual diversificação é marcado por uma contradição congênita entre as dimensões pública e privada que a compõem. A primeira refere-se aos determinantes da presença do Estado na economia, não na esfera fiscal propriamente, mas transfigurado em empresa capitalista associada à consecução de objetivos priorizados pela política econômica. A partir dos setores em que se materializa, mais freqüentemente os de insumos básicos e bens intermediários (energia, telecomunicações, siderurgia e outros), essa presença visa sustentar a rentabilidade do investimento capitalista nas demais atividades, e, portanto, na economia em seu conjunto. De uma forma mais ampla, sua razão de ser remete ao atendimento de certas condições necessárias ao avanço da acumulação de capital no âmbito de um espaço econômico específico.

O Estado, uma vez encarnado em fração particular de capital, descobre-se sujeito aos determinantes próprios de tal condição e submetido à busca compulsória de sua própria valorização. Assume, nesse momento, uma dimensão empresarial da qual esteve eximido enquanto sua ação econômica se movia nos limites da fiscalidade, contido no desempenho das chamadas "funções propriamente públicas".

A contradição que se estabelece entre a dimensão pública e a privada tende a convergir para dois pontos focais, que se condicionam mutuamente a cada situação concreta. Um, a política de preços das empresas estatais, que define o parâmetro de rentabilidade relativa na interface entre o "setor público" e os capitais privados. Outro, a política de investimentos, da qual resulta a linha fronteriça, nem sempre nítida, entre a matéria estritamente fiscal e a expansão estatal enquanto setor público. Conforme sua posição na cadeia produtiva, as empresas estatais também ganham maior ou menor importância como geradoras de demanda, o que salienta a inclusão da política de preços no problema microeconômico mais geral de formação das margens brutas de lucro dessas entidades. Nessa perspectiva, o exame de uma estatal, financeira inclusive, deve colocar em primeiro plano a evolução da natureza dos fundos com que opera e o resultado de sua gestão, como parte de uma avaliação mais abrangente das diretrizes de política econômica que ela integra.

Certamente, a passagem do nível de generalidade anterior para a discussão de circunstâncias mais determinadas não prescinde de mediações teórico-históricas, cuja mínima abordagem excederia este trabalho. No contexto da mundialização e após, pelo menos, meio século de expansão e diversificação quase generalizada do setor público, uma onda de privatizações se estende tanto sobre as economias desenvolvidas como sobre as formações capitalistas tardias, que têm uma inserção particular nesse quadro. Tal fenômeno provavelmente estabelece um novo marco das relações Estado-economia no capitalismo 
contemporâneo. Reconhecendo a relevância dessa "ponte", fica em seu lugar a hipótese provisória de que tal ausência não invalida totalmente uma aproximação dos contornos mais concretos do tema deste artigo.

Em seu desenho geral, a configuração dos bancos estatais controlados pelo governo federal brasileiro não sofreu modificação profunda dos anos oitenta aos noventa. Houve a absorção das funções e da estrutura patrimonial do Banco Nacional da Habitação e do Banco Nacional de Crédito Cooperativo, em 1986, pela Caixa Econômica Federal (CEF) e Banco do Brasil respectivamente. Na mesma data, surgiu o Banco Meridional, a partir da estatização de instituições privadas que haviam quebrado, mas esse banco foi privatizado em 1997 sem ter adquirido feição de empresa estatal. Excetuando esses episódios, o conjunto de bancos sob controle da União continua há várias décadas formado pelo Banco Nacional de Desenvolvimento e Social (BNDES), CEF, BB e pelas instituições regionais de fomento Banco da Amazônia S.A. (Basa) e Banco do Nordeste S.A. (BN).

Porém, examinando-se a estrutura patrimonial de cada instituição, ao invés da simples configuração do conjunto, emergem aspectos novos e de maior relevo. Nos anos noventa, esses bancos tiveram redefinidas sua relações com diversos instrumentos de poupança compulsória. Ora passaram a incluir, ora consolidaram em sua estrutura uma articulação mais estreita com fundos de natureza fiscal ou parafiscal, voltados, entre outros objetivos, para o fomento creditício. Em sua base normativa e mecanismos de gestão, tais fundos refletem de forma mais detalhada e imediata as prioridades da política econômica para cada área de atuação específica.

Os fundos regionais de desenvolvimento, o FNO para a região Norte e o FNE para o Nordeste, foram criados a partir da Constituição Federal de 1988, tendo como fonte principal de recursos um percentual incidente sobre o imposto de renda recolhido em cada região. Participam de suas hierarquias de comando, abaixo da lei, as superintendências de desenvolvimento Sudam e Sudene respectivamente, cabendo com exclusividade ao Basa e BN a implementação de suas operações e o risco de crédito a elas associado. Basta mencionar que, ao longo dos anos noventa, esses fundos chegaram a representar entre dois terços e noventa por cento dos passivos de cada instituição, como mostram seus balanços financeiros, para concluir que a criação desses instrumentos está na raiz do "renascimento" daqueles bancos. Da mesma forma, foi criado o FCO para a região Centro-Oeste - sendo administrado pelo $\mathrm{BB}$, na ausência de um banco regional que, embora previsto na legislação, não chegou a ser constituído.

O Fundo de Garantia do Tempo de Serviço (FGTS) apresenta-se como o maior instrumento de poupança compulsória da economia brasileira em ativos, 
proporcionando recursos para o investimento em habitação popular, saneamento básico e infra-estrutura urbana. As contas vinculadas que o alimentam encontram-se centralizadas na CEF, que é seu agente operador e também seu maior agente financeiro. As contribuições ao FGTS são feitas pelas empresas, em nome do trabalhador, com base num percentual de $8 \%$ da remuneração que lhe é paga ou devida. Ao final de 1997, por exemplo, mais de um quinto do estoque de financiamentos habitacionais da CEF e quase metade de seus depósitos correspondiam a recursos do FGTS (CARVALHO; PINHEIRO, 1999, p. 10, nota 16). Além disso, por determinação legal, a CEF passou a receber com exclusividade os depósitos judiciais, outra fonte volumosa de recursos relativamente estáveis que formam parcela substancial de seu funding.

O BNDES, por sua vez a principal agência pública provedora de crédito de longo prazo do país, passou a receber os recursos provenientes do Programa de Integração Social e do Programa de Formação do Patrimônio do Servidor Público (PIS/Pasep) a partir de 1974, incumbido de apoiar o esforço de industrialização associado ao II Plano Nacional de Desenvolvimento. A essência dessa função e as condições instrumentais para sua realização foram renovadas por meio de dispositivos da Constituição de 1988. Basicamente, as contribuições do PIS originam-se de um percentual ou da folha de pagamento ou da receita operacional bruta, no caso do setor privado, ao passo que as do Pasep vêm das receitas correntes da administração pública. Em 1990 constituiu-se o Fundo de Amparo ao Trabalhador (FAT), que recebe os recursos do PIS/Pasep, dos quais $40 \%$ destinam-se à carteira de desenvolvimento do BNDES (PINHEIRO, 1997).

Dessa forma, embora se ressentido da crise fiscal e financeira do setor público e da crescente instabilidade, a economia brasileira adentrou a década de noventa munida de um arcabouço institucional que resultou da "renovação do mandato" das instituições financeiras públicas federais. Esse arcabouço incluiu a consolidação de importantes fontes de recursos fiscais e parafiscais para atingir os objetivos atribuídos àquelas instituições, exceto em boa medida no caso do Banco do Brasil. A este banco foi destinada a "missão" especial de substituir os fundos orçamentários que sustentavam suas operações ativas por recursos mobilizados de maneira concorrencial nos mercados financeiros, tornando-se por isso um experimento qualitativamente singular na reestruturação dos bancos públicos federais ao final dos anos oitenta e nos noventa. As conseqüências de tal circunstância constituem o tema deste artigo.

O restante do trabalho aborda algumas das questões suscitadas nesta Introdução, seguindo um recorte temático que permita analisar a contradição entre sua face pública e privada no período em foco. Na segunda seção, discutem-se as relações financeiras do BB com outras entidades no que se refere às finanças 
públicas. A terceira seção detém-se nas políticas de crédito dirigidas ao setor rural, consideradas como um dos aspectos mais representativos de sua ação "pública". A quarta considera a estatal em sua "dimensão empresarial", isto é, a constituição do banco na forma de conglomerado financeiro em busca de rentabilidade. $\mathrm{O}$ aparente paradoxo entre a capitalização do banco e as diretrizes privatizantes do governo Cardoso é objeto da quinta seção. A última é conclusiva.

\section{O BB NO QUADRO DAS FINANÇAS PÚBLICAS}

A evolução dos papéis desempenhados pelo Banco do Brasil no aparelho de Estado foi marcada, a partir de fins dos anos trinta, pela constituição da Carteira de Crédito Agrícola e Industrial do BB (Creai), num período em que o setor industrial apenas ensaiava disputar a liderança da acumulação na economia brasileira. Em momento subseqüente, criou-se a Superintendência da Moeda e do Crédito (Sumoc), no interior da estrutura do BB, voltada para a regulação das condições de liquidez e operacionalização da política cambial do país. No início dos anos cinqüenta, quando a acumulação industrial assumia a liderança face às demais atividades, surgia a Carteira de Comércio Exterior (Cacex) como uma estrutura diferenciada no interior do banco - ao mesmo tempo em que era fundado o então BNDE, voltado para o reaparelhamento produtivo do país. Além disso, como "banqueiro do Tesouro", o BB alocava, em 1964, mais da metade de seus créditos no financiamento dos déficits dessa entidade.

Essa síntese de sua trajetória indica com clareza que até então o BB representava um locus de poder decisivo na definição de rumos e execução da política econômica do país. Acrescente-se nesse sentido que, embora formalmente subordinado à instância ministerial, era capaz, em determinadas circunstâncias, de agir em franca divergência com ela.

Após a instalação do governo militar, as reformas financeiras de 1964/ 65 envolveram a transformação do Conselho da Sumoc no Conselho Monetário Nacional (CMN), que se tornou o "comitê" decisório máximo da política econômica do país, enquanto as demais funções dessa Superintendência foram atribuídas ao Banco Central do Brasil (Bacen), criado nessa ocasião. O BB também se viu proibido de conceder novos empréstimos ao Tesouro, cujos déficits passaram a ser financiados com instrumentos próprios. Assim, profundamente rebaixado em seus papéis de agente financeiro do Tesouro e autoridade monetária, foi selado o horizonte da "nova" instituição Banco do Brasil, à qual não restou senão reorientar-se para a expansão de suas operações junto ao setor privado nos planos doméstico e internacional. 
Tais reformas constituíram o núcleo de um novo capítulo da diversificação do setor público brasileiro. Mais uma vez, somente no interior desse processo mais amplo é que a trajetória do BB poderia ser explicada - enquanto manifestação do Estado na qualidade de provedor de condições financeiras favoráveis à estruturação e diversificação da própria base produtiva da economia nacional - e, reciprocamente, trazer uma contribuição relevante para a compreensão do processo de mutação institucional e econômica em seu conjunto. $\mathrm{O}$ esclarecimento daquele percurso específico dependerá, ainda, da apropriada referência à inserção financeira do Brasil no contexto do endividamento externo, no qual o BB desempenhou papel de relevo.

Mesmo destituído da centralidade fiscal e monetária que deteve no período anterior, o novo BB preservou após 1964 o manejo de vultosos recursos fiscais e, em relação estrita com essa incumbência, foi dotado da capacidade de avançar recursos monetários, especialmente o crédito, livre das restrições regulatórias enfrentadas pelos demais bancos comerciais. Essa prerrogativa materializou-se na chamada "conta-movimento" do Bacen no BB, pela qual, na circunstância de as reservas obrigatórias do BB no Bacen estarem por situar-se abaixo do mínimo estipulado pela Autoridade Monetária - o Bacen -, o nivelamento automático entre um e outro era feito através de simples partida contábil emitida pelo BB. Com a vigência desse mecanismo o BB preservou a virtual capacidade de emissão, permanecendo, por isso, enquadrado na condição de "autoridade monetária" ao lado do Banco Central.

Essa estrutura híbrida e ao mesmo tempo hierarquizada perdurou até o advento de uma nova reforma das finanças públicas em 1986/88, que integrou o processo de unificação orçamentária ocorrida no período. Nesse triênio, a redefinição das relações entre o Tesouro Nacional, o Banco Central e o Banco do Brasil, ao tempo que estreitou ainda mais o lugar do BB no âmbito da política monetária e fiscal, também conduziu o banco a uma situação de crise que se projetou sobre sua situação patrimonial e financeira e que somente veio a ser enfrentada a partir de 1995.

Entre as medidas que compuseram aquelas reformas, causou impacto frontal sobre o BB o congelamento e posterior extinção da conta-movimento em 1986. Seu manejo havia permitido à instituição, por mais de uma década, executar com razoável liberdade financeira uma gama relevante de operações no âmbito do antigo orçamento monetário, orientado pelas prioridades de política econômica definidas a partir do CMN. Nesse período, assim como antes de 1964, extensão e limites de sua "dimensão empresarial" estiveram funcionalmente ajustados ao cumprimento das ações de governo: visto que o arranjo anterior proporcionava ao BB a capacidade de emissão monetária, 
sua vigência eliminava a possibilidade de problemas de liquidez do banco e o dispensava da adoção de mecanismos rigorosos de gestão financeira. Com a supressão desse mecanismo, o BB deixou de ser considerado autoridade monetária. Golpe adicional nas condições de liquidez e nos custos dos passivos da instituição ocorreu em 1988, com a transferência dos saldos mantidos voluntariamente pelos bancos comerciais e caixas econômicas no BB para o Banco Central.

A extinção da conta-movimento atendeu, por um lado, a exigências políticas e administrativas de unificar e dar transparência ao processo orçamentário. Porém, a suposta capacidade desse mecanismo inviabilizar o controle da base, comprometendo, assim, a condução da política monetária - prato forte da crítica de extração liberal -, permaneceu desprovida de uma sustentação convincente. Não apenas pela controvérsia teórica que informava os diagnósticos da instabilidade econômica brasileira naquele período, mas também porque se evidenciou que o fim da conta-movimento não conduziu ao maior controle da evolução dos níveis inflacionários, nem dos agregados monetários e nem sequer do crédito, em particular. Ao contrário, o descontrole ampliou-se (FUNDAP, 1988, p. 77).

Para o BB, entretanto, essa mudança trouxe conseqüências profundas tanto em seu alcance enquanto instrumento de política econômica como em sua dimensão empresarial. Submetido a regras de funcionamento que o aproximaram do ponto de vista regulatório dos demais bancos comerciais, perdendo a condição que chegou a ser caracterizada como a de uma "autarquia de crédito", a ação creditícia do BB tornou-se cada vez mais dependente dos "suprimentos específicos" com que passou a efetivar operações em nome do Tesouro. Porém, a liberação desses recursos através da Secretaria do Tesouro Nacional (STN), criada em 1986 para completar a nova estrutura orçamentária, não impediu que o banco ainda comprometesse com certa freqüência recursos mobilizados no mercado para atender às operações oficiais.

Entre o novo desenho institucional e a prática costumeira das finanças públicas, acabou se interpondo o agravamento da crise fiscal, de forma que adquiriu grande importância a sistemática de aporte de recursos do Tesouro: acumulavam-se atrasos, sendo comuns aqueles cobertos no interior de cada exercício, mas não era raro que ocorressem alguns de prazos mais dilatados, configurando ambos um artifício de financiamento do Tesouro. Se, de um lado, serviu para camuflar parte relevante dos déficits, essa sistemática também representou uma vertente de fragilização financeira e patrimonial do próprio banco; com isso, ganhou relevo entre os determinantes da rentabilidade cadente da empresa a acumulação de passivos do Tesouro junto ao BB não reconhecidos ou não honrados. 
O processo de reforma orçamentária e fiscal teve continuidade em 1988. A nova Constituição Federal estabeleceu, em seu artigo 164, que as disponibilidades de caixa da União deveriam ser depositadas no Bacen, perdendo o BB grande parte de sua função de "caixa" do Tesouro, o que significou uma perda próxima a US\$ 7 bilhões em depósitos até então não remunerados. A nova configuração das relações BB-Bacen-TN completou seu desenho com o aperfeiçoamento da estrutura orçamentária associado à criação do Orçamento das Operações Oficiais de Crédito, vinculado ao Orçamento Geral da União, incorporando um amplo conjunto de atividades financeiras do BB (GUARDIA, 1993).

Sem adentrar em uma avaliação das reformas das finanças públicas empreendidas em 1986/88, seja quanto a sua orientação básica seja, quanto à possibilidade de que, estando essencialmente no rumo certo, tenham ficado aquém da profundidade necessária e/ou desacompanhadas de outras medidas adequadas, cumpre, de qualquer forma, recordar que o agravamento da instabilidade macroeconômica não foi detido nesse momento e nem no período seguinte. Todavia, inclui-se entre suas conseqüências o fato de que fragilizaram o $\mathrm{BB}$ em sua estrutura financeira na medida que promoveram o encarecimento médio de seu funding, submetendo-o às vicissitudes do mercado. As reformas, assim como o coetâneo processo constituinte, não definiram novas fontes de recursos baratos e estáveis para o crédito à atividade agropecuária e outras "missões" que permaneceram atribuídas à instituição.

Mais adiante, certas vantagens operacionais associadas ao papel de agente financeiro do Tesouro também foram sendo erodidas. Em 1991, por exemplo, no contexto do programa de liberalização do governo Collor, o Banco do Brasil perdeu a exclusividade do recolhimento dos tributos federais e do fechamento de câmbio das estatais. Enquanto estas ganharam liberdade para estreitar seus laços com as corporações financeiras privadas, a decisão acentuou o declínio da rentabilidade do banco e concorreu para diminuir sua participação no mercado de câmbio.

A partir de 1995, com a instalação do governo Cardoso e a continuidade do plano de estabilização, o "Real", a relação Tesouro-BB passou por novas e decisivas modificações. Com o alegado propósito de conferir maior consistência fiscal ao plano, o governo se dispôs a praticar uma ampla consolidação de dívidas, explicitando e regularizando alguns passivos do Tesouro pendentes com órgãos da administração indireta - os chamados "esqueletos no armário". As negociações com o BB em torno dos valores devidos ocuparam lugar de destaque, ao lado dos acertos da Siderbrás, da conta-petróleo, FCVS e outros. Embora muitos procedimentos não tivessem sido regularizados ou nem sequer registrados, o BB foi acumulando ao longo dos anos um "crédito" oculto e 
volumoso devido ao papel de financiador informal do Tesouro. $\mathrm{O}$ valor reivindicado pelo então diretor de Finanças na CPI do BB, em 1991, foi de US\$ 8,3 bilhões. Em 1995, o banco pleiteou ao Tesouro Nacional o ressarcimento de R\$ 5,2 bilhões, obtendo como resultado inicial o reconhecimento de $\mathrm{R} \$ 2,3$ bilhões e a progressiva ampliação do valor após essa data.

Esse acerto de contas, instalado pela Portaria MF 150, de 26/04/95, lançou um pouco mais de luz sobre o caráter da relação financeira entre o Tesouro e o BB nas últimas duas décadas . Um primeiro grupo do passivo compunha-se de comissões sobre empréstimos realizados pelo banco como agente financeiro do Tesouro. Foi o caso das operações com o Instituto de Açúcar e do Álcool, Instituto Brasileiro do Café, Rede Ferroviária Federal, programa nuclear brasileiro e com o Departamento Nacional de Estradas de Rodagem. Outra parcela referia-se a empréstimos simplesmente não retornados, concedidos a órgãos federais e autarquias ou sob garantia do Tesouro, nos quais o BB agiu sob orientação governamental, sendo os mais volumosos os concedidos a estaleiros privados, com garantia da Sunaman.

Algumas pendências dizem respeito a equalizações de taxas de juros ou adicional sobre a remuneração de empréstimos a taxas favorecidas, incluindo-se programas de irrigação, créditos referentes às safras de 1991 e 92 e a construção da Linha Vermelha, no Rio de Janeiro, em 1991. O BB ainda honrou fianças e avais de empréstimos, como na inadimplência da Cooperativa de Produtores de Açúcar de Alagoas, em 1991, junto ao Midland Bank Plc, de Londres. O ressarcimento de serviços executados pela Cacex antes e depois da transferência de suas funções para a administração direta também atingiu elevado montante. Resta mencionar algumas operações especiais, como a sustentação do preço internacional do café, quando o $\mathrm{BB}$ fez volumosas compras junto a empresas salvadorenhas, em fins dos anos setenta, sem receber o produto nem ressarcimentos.

Deve-se acrescentar que mesmo os valores reconhecidos não correspondem a um cálculo financeiro rigoroso, pois o acerto não se baseou no custo de oportunidade dessas posições. Um exemplo conspícuo é o "rombo" da ordem de US\$ 1 bilhão que o BB carregou ao longo de 1989, devido ao fato de os créditos rurais, lastreados com recursos captados através da caderneta rural, terem sido corrigidos por um índice inferior ao custo desse instrumento de captação. O carregamento de um "portfólio de longo prazo" da dívida externa, em torno de US\$ 5 bilhões, constitui outro exemplo destacado. Por trás das operações malsucedidas que integravam aquele portfólio - as "polonetas", cobertura de atividades da construtora Mendes Júnior no Oriente Médio, defaults de países latino-americanos e africanos, entre outros -, escondia-se, entrelaçada, par- 
te relevante do custo representado pela cobertura financeira à expansão comercial brasileira e da diplomacia "terceiro mundista".

A tese de que se o passivo consolidado do Tesouro fosse gerido pelo BB sob ótica eminentemente empresarial seria muito superior ao que foi apurado, aventada quando da regularização dos devidos valores a partir de 1995, faz sentido estritamente econômico. Mas não resiste a uma ressalva crucial: se a "racionalidade empresarial" tivesse presidido a ação do Estado e a gestão do BB no período que correspondeu à formação desse passivo, ele talvez nem tivesse sido constituído nas condições em que se verificou. Em outras palavras, tanto a formação desse passivo quanto seu reconhecimento formal, antes de obedecerem a uma racionalidade de mercado e terem nesse critério a ótica adequada para sua avaliação, estiveram prioritariamente pautados por diretrizes de política econômica.

\section{FOMENTO CREDITÍCIO À ATIVIDAdE RURAL: A FACE PÚBLICA}

O "sistema" de financiamento do comércio exterior brasileiro passou por uma reforma nos anos oitenta que pode ser considerada exitosa no sentido de retirar o Estado da posição dominante que ocupava - caso sua presença seja abastraída através de outros instrumentos, como o poderoso estímulo representado pelo ativismo da política cambial favorecendo as exportações. Do virtual monopólio que o BB exercia no início da década nas linhas de médio e longo prazos, garantindo-lhe maioria absoluta dos contratos fechados nos mercados cambiais, sua participação em valor decresceu ao final do período para aproximadamente um quinto do total. Valer dizer, o BB perdeu a centralidade que exercia no financiamento do comércio exterior ao se privatizarem as fontes de recursos que amparavam essa finalidade.

Ao contrário disso, a sustentação das atividades rurais e conexas preservou como seu eixo a distribuição do crédito subsidiado através de agentes públicos, de forma que o BB se manteve como estrutura vertebral do Sistema Nacional de Crédito Rural (SNCR) desde sua criação em 1965. Com as dificuldades da economia e do setor público nos anos oitenta, dois movimentos materializaram a reestruturação do SNCR: o decréscimo substancial dos fluxos de recursos, caindo de valores próximos a US\$ 20 bilhões no início dos anos oitenta para menos de US\$ 10 bilhões na virada da década, ao lado da progressiva extinção dos subsídios - processo que se chamou de "reforma do crédito rural". Não obstante, até hoje em torno de dois terços do volume total de crédito bancário destinado ao setor agropecuário são distribuídos através do Banco do Brasil.

Com a estabilização proporcionada pelo Cruzado em 1986, suprimi- 
ram-se as regras de indexação dos contratos de crédito. Ao mesmo tempo, o setor rural foi beneficiado com maior volume de recursos devido à expansão dos depósitos à vista no $\mathrm{BB}$, cujos saldos passaram de US\$ 5,5 bilhões para US\$ 14,7 bilhões entre o final de 1985 e do ano seguinte. Recorde-se que data de 1986 a extinção da conta-movimento; foi precisamente esse detalhe, a remonetização e o aumento dos depósitos à vista no $\mathrm{BB}$, que permitiu que o fim da conta-movimento não implicasse conseqüências nefastas para o financiamento do setor. Em 1987, a política de crédito consistiu basicamente na administração da crise de liquidez que sucedeu o fim do plano. A reaceleração inflacionária e a reindexação dos contratos rurais geraram uma conjuntura extremamente adversa a um amplo conjunto de devedores. Coube então ao BB, na condição de agente financeiro do Tesouro, ser o principal instrumento refinanciador das dívidas do setor privado, rural e do segmento das micro, pequenas e médias empresas urbanas, assim como das dívidas do setor público em instância subnacional.

Esse papel foi desempenhado ao custo de um maior comprometimento de sua solidez financeira, seja porque o volume de refinanciamentos efetivados acabou excedendo os limites deliberados pelo CMN, seja porque o exercício dessa função de "emprestador de penúltima instância" alimentou expectativas de novas facilidades para os inadimplentes. Assim, a fragilidade financeira então concentrada em devedores privados foi transferida, a partir de 1988, para o BB e impactou ainda o Tesouro Nacional. Adicionalmente, deliberou-se, no âmbito da Constituinte, a concessão de uma anistia da correção monetária dos contratos dos mini, pequenos e médios produtores rurais, e dos pequenos e médios empresários urbanos, assumidos durante o Cruzado, cuja carga incidiu em parte sobre as contas do banco.

Como uma das principais conseqüências dos atrasos, prorrogações, refinanciamentos e da anistia, bem como do estímulo à inadimplência dado pelo ministro da Agricultura e líderes de classe, disseminou-se a percepção da vulnerabilidade do agente financeiro oficial. Face à perspectiva de limitação de crédito, tornou-se racional para uma parcela crescente dos agentes privados simplesmente não retornar os recursos devidos e aguardar as medidas de acomodação. Esse comportamento não se traduziu de imediato em inadimplência. Primeiro, porque houve uma primeira parte dos refinanciamentos efetivada com recursos orçamentários. Segundo, pela prática do BB de reter uma parcela dos novos recursos para liquidar operações anteriores, conhecida como "mata-mata". É impossível quantificar a extensão dessa prática, por ser ilegal, mas parece ter sido de aplicação muito comum pelo menos até 1994.

A atuação do Banco do Brasil na segunda metade dos anos oitenta, 
após o fim da conta-movimento e de nova tentativa de implantar uma ênfase comercial em sua dinâmica de empresa financeira, evidencia que a lógica da instituição continuou diferenciada daquela que preside o comportamento dos agentes financeiros privados. Enquanto estes priorizam seletivamente liquidez, risco e rentabilidade, o agente estatal age sobrepondo a tal percepção a orientação "pública" das autoridades econômicas, voltada para a sustentação da renda e condições de operação de setores não-financeiros. A partir de então, podemse identificar regularidades onde políticas financeiras, destacadamente a expansão do crédito do $\mathrm{BB}$, contribuem, num primeiro momento, para a expansão econômica; em seguida, a reversão compromete a situação financeira do setor privado e, por fim, transfere-se a fragilização para o setor público, que em boa medida fica contabilmente camuflada na deterioração patrimonial do BB. Até 1986, havia um "atalho" nesse percurso que imunizava o instrumento financeiro diante do processo de socialização de perdas, representado pelo acionamento da conta-movimento.

Em resumo, as mudanças ocorridas na segunda metade da década passada não tornaram o SNCR secundário no apoio às atividades agropecuárias, mas essa política ressentiu-se do impacto da crise fiscal, traduzida na queda do volume de crédito e na elevação das taxas. O BB preservou sua posição central no sistema, com modificações drásticas nas condições em que desempenhava esse papel. Embora mantido como instrumento de governo, passou a apoiar-se prioritariamente em recursos mobilizados no mercado, tanto que, ao final dos anos oitenta, mais da metade dos fundos mobilizados para o crédito rural já era de origem concorrencial e em torno de um quarto apenas tinha natureza orçamentária, invertendo a posição de meados da década. Assim, o estreitamento do SNCR como um todo refletiu a diminuição do alcance do BB na sustentação da política de crédito rural, ao mesmo tempo que sua permanência como agente central do sistema representou o fracasso das políticas que pretendiam retirar do Estado essa atribuição, nos anos oitenta.

$\mathrm{Na}$ década de noventa essas conclusões, em linhas gerais, permanecem válidas. O ano de 1990 representou um ano de volume mínimo na trajetória do crédito rural, cuja queda superou a da produção agrícola (40\% e $11 \%$, respectivamente). O Plano Collor agravou esse quadro, confiscando a liquidez no momento em que se iniciava a comercialização da safra de verão; e, ao submeter a política agrícola à de estabilização, reduziu a demanda de produtos agropecuários, levando a uma queda dos preços e da renda agrícola apesar da menor oferta de produtos. Em decorrência, ganhou impulso a campanha de refinanciamento desencadeada por sojicultores do Centro-Oeste e rizicultores do Sul, regiões que absorvem a maioria relativa do crédito rural do BB. Diante 
disso, o governo adotou a prorrogação de contratos com recursos da poupança, dos quais o BB é o grande agente, ao qual coube ainda implementar medidas complementares para o setor agropecuário atravessar o momento mais delicado da falta de liquidez.

Resultado das safras colhidas até meados de 1991 e dos impactos negativos sobre os preços, a rendição da política "neoliberal" significou retomar a defesa de condições favoráveis aos produtores. Porém um dos principais problemas para a agricultura, senão o central, permaneceu sendo a insuficiente disponibilidade de crédito em condições adequadas. Em 1992, ano do impeachment do presidente da República, o quadro político possibilitou à bancada rural, no Congresso, retomar alguns instrumentos de proteção ao setor. Mas a restrição de recursos refletiu-se também no não pagamento, pelo Tesouro Nacional, das equalizações entre os custos de captação do BB no mercado e o retorno dos empréstimos aos agricultores relativas às safras agrícolas de 1991/ 92, cujo valor, somado às pendências até 1995 do Proagro Novo, o programa de seguro de crédito rural, atingiu quase $\mathrm{R} \$ 800$ milhões.

Ao longo de 1991-94, a tentativa de reverter essa política revelou sua incapacidade para constituir um novo modelo de financiamento, inclusive por esbarrar nos mesmos obstáculos que o discurso da liberalização encobria, isto é, a crise fiscal, os limites à mobilização de recursos pelo BB através da ação concorrencial e a seletividade do crédito praticada pelas instituições financeiras privadas. A pendência fundamental continuou sendo a política de crédito. Assim, a reforma do crédito rural dos anos 80 e seus desdobramentos não consolidaram um padrão alternativo de financiamento da atividade agropecuária.

A rigor, o modelo anterior foi substituído por um novo esquema marcado pela precariedade, associada à recorrente escassez de fundos, e à imprevisibilidade inerente ao conseqüente conflito de interesses entre a representação política do setor e a orientação da política econômica. A reação do setor contra o fim dos subsídios passou a impor sucessivas reciclagens das dívidas em escala crescente, envolvendo abatimentos, anistias e alongamento de prazos. Dessa forma, o esquema de cobertura financeira do setor pelo Estado poderia ser caracterizado primeiro pela diminuição substancial dos subsídios creditícios, segundo pela substituição das fontes tradicionais do SNCR e, finalmente, pelas imprevisíveis mas muito prováveis renegociações em larga escala, evidenciando, por um lado, seu caráter precário e, por outro, o comprometimento patrimonial da instituição responsável por sua viabilização.

O governo Cardoso anunciou a intenção de reformular o esquema de apoio ao setor. Como novo instrumento creditício foi criada a cédula de produto rural (CPR), um título de emissão privada contra entrega futura de produto, 
concebido para ser adquirido pela agroindústria processadora ou compor as carteiras de investidores institucionais, denotando uma opção pelos segmentos mais rentáveis da agropecuária e agroindústria uma vez que somente eles têm capacidade de emitir esses papéis. Como indicação do seu alcance restrito, a CPR mobilizou, até aqui, poucas centenas de milhões de reais. Outros elementos de modernização foram introduzidos particularmente na comercialização e sustentação de renda, incorporando as inovações financeiras no campo dos derivativos, como os leilões eletrônicos e os contratos de opções, em detrimento da política de preços mínimos.

Porém, contrariando a intenção mais uma vez reiterada de desembaraçar-se desses compromissos, os reveses enfrentados pela agricultura na primeira safra do plano Real, bem como fatores políticos subseqüentes, impuseram ao BB reeditar seu "papel social" diante do setor. Como reconheceu o próprio governo: "[...] o centro das dificuldades da agricultura foi, paradoxalmente, a concretização de safras recordes, que acabaram provocando queda nos preços dos produtos de origem rural, o que veio deprimir as receitas dos agricultores" (MINISTÉRIO DA FAZENDA, 1995a). O documento agrega outros elementos a esse quadro de dificuldades, como a correção das dívidas pela TR a taxas superiores à evolução dos preços recebidos pelos agricultores, a política cambial desfavorável à concorrência com importações e, por fim, a abertura comercial nos anos 90 sem as devidas salvaguardas, além de tocar em aspectos tributários. Convém salientar que esse diagnóstico foi formulado no âmbito do Ministério da Fazenda, ao qual se subordina o Banco do Brasil, e não, por exemplo, pelo Ministério da Agricultura, mais permeável aos interesses corporativos dos produtores rurais. Diante disso, a política de súbito racionamento de crédito, como a que foi aplicada pelo BB em 1995, se não surpreende pelo seu impacto negativo, suscita certa perplexidade quanto às razões de sua adoção.

A inadimplência já atingia a ordem de vários bilhões de reais em 1995, quando foi equacionada através de um vasto programa de securitização e alongamento das dívidas bancárias dos produtores rurais, contraídas até novembro desse ano, vencidas ou em ser, dentro ou fora das regras do SNCR. Os termos da Lei 9.138 e outros normativos diretamente negociados entre a chefia do Poder Executivo e a bancada ruralista autorizaram o Tesouro a emitir até R\$ 7 bilhões para viabilizar esse programa.

A securitização consistiu em substituir nos ativos das instituições financeiras parte dos créditos concedidos ao setor privado por títulos do Tesouro Nacional, de 20 anos, que esses devedores foram obrigados a comprar e entregar aos bancos. O pagamento correspondeu a $10,36 \%$ do valor do principal da dívida; como esses títulos são de 20 anos e a taxa de desconto considerada foi 
$12 \%$ ao ano, o agente financeiro resgatará no vencimento o valor daquele principal. Os rendimentos dos títulos, por sua vez, deverão cobrir a diferença entre o custo de captação dos recursos pelos bancos e os encargos a serem pagos pelos devedores, estipulados em 3\% ao ano mais a variação dos preços mínimos . Vale dizer, uma componente da dívida foi securitizada e outra foi alongada, pressupondo pagamentos periódicos cujo risco de inadimplência corre por conta da instituição financeira.

Na primeira etapa dos entendimentos foram consideradas enquadráveis aquelas operações até o limite de $\mathrm{R} \$ 200$ mil por mutuário, alongando a concessão dos recursos por sete anos, com um de carência (ou dez, com dois de carência, conforme o caso). Essa decisão alcançou um volume de créditos da ordem de $\mathrm{R} \$ 7,5$ bilhões, dos quais em torno de $\mathrm{R} \$ 5,5$ bilhões concentrados no $\mathrm{BB}$. Posteriormente, os contratos acima daquele valor e anteriores a 1995 também foram incluídos na renegociação através do Programa Especial de Saneamento de Ativos (PESA), beneficiando-se de condições favorecidas e alongamentos que poderão estender-se por mais de uma década. Os créditos às cooperativas, da mesma forma, foram contemplados com um programa específico de renegociações (Recoop), ainda em curso. Note-se que mesmo as condições estabelecidas desses programas já foram superadas por novas concessões arrancadas pela "frente parlamentar da agricultura", o que, antes de significar uma excepcionalidade, parece integrar a própria lógica da relação desse setor com o governo.

Em resumo, o Banco do Brasil atravessou os anos oitenta e ainda permanece como principal agente da política de crédito rural, provendo condições financeiras diferenciadas à acumulação de capital nesse setor. A seção seguinte analisa as circunstâncias sob as quais esse objetivo foi perseguido, colocando em evidência o conflito inerente com a busca de rentabilidade imposta pela sua condição enquanto grande empresa financeira.

\section{CONGLOMERAÇão E RESULTADOS: “DIMENSÃO PRIVADA” DE UMA ESTATAL}

Após a extinção da conta-movimento, o BB passou a atuar na condição de instituição financeira submetida à restrição de reservas como os demais bancos comerciais, daí avançando rumo ao aprofundamento concorrencial no mercado financeiro. A penetração em novos segmentos e a constituição de novas empresas bem como a deterioração da situação patrimonial e de resultados da instituição constituem o tema desta seção. 


\section{A FORMAÇÃo do CONGLOMERADO FINANCEIRO}

A caderneta de poupança rural - um produto semelhante à caderneta de poupança imobiliária, mas que canaliza compulsoriamente por volta de dois terços dos recursos captados para empréstimos ao setor rural - constituiu a inovação financeira de maior alcance no âmbito do SNCR e da atuação do BB na segunda metade dos anos oitenta. Como nesse caso o spread, isto é, o diferencial entre as margens de captação e aplicação, é reduzido, o agente financeiro recebe adicionalmente uma "equalização" na forma de recursos mobiliários aportados pelo Tesouro Nacional. O propósito original desse arranjo era limitar a participação do Tesouro estritamente aos subsídios, deixando ao agente a incumbência de mobilizar a grande maioria daqueles fundos. Como visto há pouco, a securitização da dívida impôs uma sensível ampliação na participação dos recursos de natureza orçamentária.

Devido ao arcabouço normativo do sistema financeiro brasileiro, o lançamento de diversos outros produtos exigiu a formação do conglomerado Banco do Brasil, que apresentou duas etapas de maior dinamismo em sua diferenciação. No período 1986-88, o BB estabeleceu cabeças de ponte nos segmentos de mercado de capitais, administração de fundos, crédito ao consumidor, cartões de crédito e leasing, através da constituição de subsidiárias sob controle integral. Uma vez constituídas, porém, essas empresas tiveram sua expansão tolhida por normas restritivas que marcaram a regulação dos mercados financeiros no auge da instabilidade econômica, o que provocou uma certa hibernação das subsidiárias.

A experiência mais ambiciosa delineou-se em 1988-89, com a criação de um banco de investimento (BB-BI) com o qual se tentou deslanchar um programa de apoio à reestruturação de um variado leque de setores industriais. Esperava-se, com isso, diversificar seus mercados e fontes de receitas. Porém, no contexto de instabilidade macroeconômica que marcou aquele biênio, o projeto acabou por se revelar uma iniciativa algo voluntarista e foi abandonado no governo seguinte.

Num segundo momento, já na década dos noventa, o BB avançou para a previdência privada complementar, vislumbrada como nova fonte de recursos baratos, estáveis e de longo prazo para compor seu funding, além da capitalização e diversos subsegmentos do ramo segurador. Nesses casos, a estratégia de ingresso nos novos mercados comportou uma variação importante. Optou-se por uma composição acionária em que o BB passou a deter apenas a maioria relativa, e não o controle isolado das empresas, o que não o impediu de liderar o acordo de acionistas que comandava cada uma. Alguns motivos para essa 
nova configuração são identificáveis. Por não caracterizar uma nova estatal, sua constituição dispensa a aprovação do Congresso Nacional. Além disso, a participação minoritária permitiu ao banco eleger parceiros privados com posições já consolidadas em cada setor. Finalmente - e este é um fator explicativo de difícil avaliação - livrou-se de algumas limitações administrativas próprias das empresas estatais, inclusive no que diz respeito à política de pessoal e contratação de dirigentes.

A composição de um conglomerado sob crescente impulso de diversificação provavelmente seguiu a estratégia de explorar sinergias potenciais, construindo economias de escala e escopo obtidas a partir da rápida difusão das inovações financeiras e dos canais de distribuição pré-existentes representados pelo banco comercial do BB, de longe a rede mais capilarizada do mercado brasileiro. Note-se adicionalmente que algumas subsidiárias, como a seguradora, deveram seu desenvolvimento inicial ao "endomarketing", explorado por meio de metas de vendas impostas ao numeroso corpo de funcionário do banco comercial, e à ocupação do mercado, constituído pelos respectivos núcleos familiares. Esta é uma perspectiva pela qual se pode analisar a racionalidade que presidiu a dinâmica expansiva e diversificadora dessa estatal financeira, desde que se tome, na devida conta, a precedência lógica da consideração feita a seguir.

Diversas análises consideraram que a conglomeração do BB consistiu numa "compensação" à perda da conta-movimento. Essa hipótese, não de todo inadequada, parece insuficiente para identificar o móvel subjacente àquele processo. A diferenciação e diversificação estrutural do Banco do Brasil, desenvolvendo novos instrumentos/produtos e criando subsidiárias nos diferentes segmentos financeiros, define um movimento cujo sentido ultrapassa obter funding adequado para contra-arrestar sua fragilização enquanto grande empresa financeira. Mais amplamente, o cerne do problema remete ao desafio que se defrontou o Estado nas circunstâncias marcadas pela profunda crise fiscal e financeira do setor público, qual seja, alcançar a substituição dos recursos necessários ao atendimento de setores priorizados pela política econômica. Essa foi a mudança essencial na interface Estado/economia materializada pelo BB a partir daquele momento: sua nova inserção no arranjo das finanças públicas e a relevância adquirida por mecanismos de mercado na sustentação das políticas oficiais de crédito.

No governo Cardoso, duas novidades inscreveram-se na trajetória do conglomerado. Primeiro, agindo sob orientação do governo no estímulo e proteção às exportações, o banco decidiu liderar a formação da Companhia de Seguro de Créditos à Exportação, embora com uma participação menor que a 
do conjunto dos bancos privados e ainda inferior à da estatal francesa que detém maioria relativa do capital, a Coface. Segundo, na área do recém lançado sistema financeiro imobiliário, que visa criar instrumentos e instituições para desenvolver o segmento imobiliário comercial voltado para o atendimento das faixas de renda média e alta, o BB integrou a Companhia de Securitização de Certificados de Recebíveis (Cibrasec), passo inicial de seu ingresso no setor. Ambas acrescentaram novos elementos qualitativos à estrutura do conglomerado, embora tenham apresentado resultados pouco expressivos no período inicial de funcionamento.

O aspecto mais significativo da diversificação estrutural do banco nos anos noventa foi o fato de o BB tornar-se líder na "indústria de fundos financeiros" no país, com uma participação relativa ao redor de $20 \%$ dos recursos captados através das múltiplas modalidades oferecidas nesse mercado. A marca, a rede de agências, os numerosos tipos de pagamentos feitos pelo banco e a consolidação de uma postura concorrencial mais agressiva, mais do que a rentabilidade - visto que os fundos do $\mathrm{BB}$, em geral mais conservadores, não se incluíram entre os campeões de desempenho -, contribuíram para esse sucesso.

Entretanto, a direção do BB amadureceu em 1997 a decisão de privatizar a BB-DTVM e a BB-Securities, respectivamente a corretora em operação no país e a corretora sediada em Londres, passando-as do grupo de subsidiárias integrais para o grupo daquelas que não detinham o controle acionário. O principal argumento em favor da decisão foi a necessidade de o banco eleger um parceiro estratégico no cenário internacional, o que não respondia à objeção de que, de um ângulo estritamente mercadológico, seria possível estabelecer tal parceria vendendo um pacote acionário sem abrir mão do controle. De qualquer forma, a privatização dessas subsidiárias do BB não se consumou no primeiro governo Cardoso devido à retração do mercado internacional de capitais depois da crise russa. Já no segundo governo, a proposta foi alvo de críticas veladas e abandonada pela nova orientação da instituição (gestão Andrea Calabi), no contexto da controvérsia "desenvolvimento versus estabilização", travada no interior da base governista.

A conclusão que parece emergir da trajetória de formação do conglomerado, incluindo esse último episódio, é que o propósito de imprimir um caráter eminentemente privado a sua gestão corrente e a todo o processo de expansão e diversificação da estatal financeira acabou encontrando certos limites estruturais, que se impõem como contraparte da precedência ocupada por sua lógica de empresa pública. Em outras palavras, a mesma ordem de determinações que preside a formação do conglomerado também estabelece o horizonte de seu desdobramento. Isso não exclui que uma conjuntura específica abra espaço à 
prevalência de sua dimensão empresarial, ou mesmo, numa possibilidade extrema, que o conglomerado seja parcial ou em seu todo privatizado; afirma-se apenas que não seria essa a resultante previsível da ação das forças econômicas e sociais subjacentes a sua dinâmica atual.

\section{RESULTADOS EM DECLÍNIO}

O desempenho do BB, avaliado através de seus resultados financeiros, guarda estreita correspondência com a evolução de sua inserção no quadro das finanças públicas. Enquanto deteve a posição de autoridade monetária, a rentabilidade do Banco do Brasil manteve-se em patamares elevados. Em 1985, último ano em que pôde dispor da conta-movimento, o lucro da instituição alcançou valor próximo a US $\$ 2,0$ bilhões. No ano seguinte, sob um curto período de estabilidade e sem aquele mecanismo, a performance reduziu para US\$ 400 milhões; a razão principal foi o baixo retorno dos empréstimos, apesar de o banco ter liderado a expansão do crédito sob o cruzado. A partir desse ponto, instalou-se em suas contas uma tendência ao declínio dos resultados, cujo afloramento espelhou a trajetória de deterioração patrimonial e de fragilização econômico-financeira da instituição, que veio a ser enfrentada mais seriamente apenas no início do Plano Real.

A crise de resultados de 1986 a 1993 pode ser sintetizada em duas vertentes mais ou menos definidas. A primeira diz respeito aos impactos das reformas institucionais de 1986/88 em seu funding, reduzindo os recursos orçamentários, mais baratos, com que o Banco do Brasil historicamente havia operado, daí se projetando em sua estrutura de despesas. O fim da conta-movimento, a retirada dos depósitos à vista de várias instâncias de governo, a diminuição dos repasses originados do Tesouro, e, no lugar desses recursos, a posição predominantemente tomadora no interbancário, a relevância assumida pela caderneta de poupança rural e outras fontes mais onerosas fazem parte dessa trajetória.

A segunda vertente manifestou-se pelo lado de suas operações ativas. A reação dos produtores à reforma do crédito rural, conseguindo aprovar anistias e diversas outras medidas de alívio financeiro, provocou um efeito negativo sobre a qualidade das operações do banco em episódios que foram se tornando quase que regulares, afetando a estrutura de prazos dos contratos de crédito. Note-se que entre os beneficiários dessas medidas incluíram-se ainda, em algumas ocasiões, segmentos de devedores urbanos, industriais e comerciais. Os refinanciamentos e alongamentos, ao estreitar os níveis de liquidez da empresa, agravaram suas condições financeiras e o crescente descasamento dos prazos entre captações e aplicações. Além disso, sua deterioração patrimonial expres- 
sou-se na degradação das garantias associadas aos contratos de crédito, que contribuiu para a elevação dos níveis históricos de inadimplência. Como conseqüência da ação combinada dessas duas vertentes fragilizadoras atuando pelo lado de suas operações ativas e passivas, a deterioração da estrutura de resultados do BB a partir da virada da década expressa plenamente sua crise na dimensão empresarial, embora não esgote seu alcance.

Após o cruzado, os resultados do BB retornaram no biênio 1987/88 a patamares próximos a US\$ 1 bilhão, como efeito contábil dos refinanciamentos praticados em larga escala. Entretanto, declinaram ainda mais os recursos baratos disponíveis para a instituição, destacando-se a perda de US\$ 7 bilhões em depósitos à vista mantidos pelo governo, também decorrente das reformas das finanças públicas. Em 1989, o BB apresentou o resultado mais baixo de sua história até então, da ordem de US\$ 115 milhões. Nesse ano, o Plano Verão provocou um descasamento da poupança, principal fonte de recursos do BB e do financiamento agrícola, cujos depósitos foram corrigidos acima das operações ao setor; o BB carregou esse "rombo" de mais de um bilhão de dólares ao longo de quase todo o ano.

Não dispondo mais da conta-movimento, as prorrogações e refinanciamentos por sua própria conta atingiram negativamente o Banco do Brasil, independente de serem ou não operações originalmente financiadas pelo Tesouro. Como agravante, os resultados artificiais assim obtidos implicaram a distribuição de dividendos e pagamentos de impostos, gerando um segundo impacto na liquidez do BB, que se tornou, já ao final da década, captador líquido de recursos no mercado interbancário.

Nos anos iniciais da década de 90, a estrutura de resultados do BB modificou-se, passando a depender de itens não operacionais, particularmente os associados a investimentos externos e à valorização cambial. Em 1991, quando foi empreendida uma primeira tentativa de "ajuste de posição", seu resultado operacional adveio dos ganhos com a inflação e da reversão de provisões formadas naquele ajuste. Em 1992, os ganhos com a inflação, ao lado das "receitas de empréstimos, cessões e repasses" e das "outras receitas e despesas operacionais" - volumosas, e não explicitadas no balanço - sustentaram o resultado do banco no exercício. Tais indicações, além de revelar uma ruptura em seu padrão de receitas - com a diminuição do peso relativo das receitas do crédito e a ascensão dos ganhos com a inflação -, sugerem que foram socorros meramente contábeis por parte do Tesouro que permitiram ao banco evitar a explicitação de prejuízos já no início da década de noventa. 


\section{REESTRUTURAÇÃO: GESTÃo “EMPRESARIAL” OU REESTATIZAÇÃo?}

O afloramento da crise do BB previsivelmente viria a colocar o governo Cardoso face ao dilema de como encaminhar sua reestruturação e, em essência, que rumo dar a esse processo: manter o caráter estatal do conglomerado ou lançar as bases de sua futura privatização. Uma indicação importante dos obstáculos a esta segunda opção reside no fato de o BB não ter sido incluído no Programa Nacional de Desestatização (Dec. 1294/94). Mas, a partir de 1995, essa restrição seria posta em xeque, pois, sob o regime do real, a tendência de resultados adversos manifestou-se, por fim, em prejuízos talvez sem precedentes na história financeira mundial. A identificação dos determinantes do primeiro grande prejuízo da instituição em muitas décadas, ocorrido no primeiro semestre de 1995, é fundamental para o entendimento da dimensão espantosa que afinal tomou esse processo de ajuste.

O semestre anterior à estabilização foi muito favorável às instituições financeiras. Quanto ao BB, os ganhos com a inflação superaram os dos cinco grandes bancos privados em conjunto; entretanto, tais ganhos basearam-se no volume de depósitos à vista, dos quais a maior parte era do governo federal. Quanto às operações de crédito, suas receitas nesse semestre foram maiores que em todo o ano de 1993 - embora caiba questionar novamente a qualidade e sustentabilidade desse resultado. Diante do aumento da anormalidade que já se desenhava àquela altura, há indícios de que o próprio banco teria induzido renegociações em larga escala para poder fechar o balanço "no azul".

Com a queda da inflação, o BB apresentou um pequeno prejuízo logo no segundo semestre de 1994. As receitas de intermediação financeiras, entre as quais se destacam as oriundas das operações de crédito, caíram em maior proporção que as correspondentes despesas; na mesma direção, a drástica redução dos ganhos com a inflação foi acentuada pela retirada de recursos do setor público . Finalmente, a valorização cambial do início do real, ao desvalorizar os ativos do banco no exterior, também provocou forte impacto contábil no resultado.

Nessas circunstâncias, tomou posse a nova diretoria do Banco do Brasil, nomeada pelo presidente Cardoso no início de 1995, que viria a ser uma das mais longas e estáveis gestões de sua história. Nesse semestre também aflorou a situação de colapso no desempenho do banco, que apresentou um prejuízo de R $\$$ 2,4 bilhões. Seu balanço mostra que o "fato relevante" de maior importância para o prejuízo foi o provisionamento para devedores duvidosos, principal impacto contábil da inadimplência; a causa desse fato não residiu na adoção de critérios 
mais conservadores para o provisionamento e sim no próprio fato gerador.

Aí se impõe destacar a nova postura da direção da empresa, que ao negar-se a reciclar os débitos nos moldes convencionais jogou um papel decisivo para que a anormalidade das operações assumisse a magnitude finalmente alcançada. Devido à nova diretriz na gestão do crédito, chamada pelo banco de "mudança do paradigma de negociação", a inadimplência acabou por atingir níveis certamente mais elevados do que teria assumido se fosse levada em conta a conjuntura adversa enfrentada pelo setor rural, reconhecida pelo próprio governo (Cf. MINISTÉRIO DA FAZENDA, 1995a).

Mais ainda. A situação de crise latente na agricultura esteve por trás da negociação conflituosa mantida pela "bancada ruralista" no Congresso Nacional junto ao Poder Executivo . A relação atingiu o ponto de fervura com a rejeição, pelo Congresso, do veto presidencial à eliminação do uso da TR como indexador dos contratos vencidos e em ser. Frente a essa situação, a direção do BB adotou em represália o corte imediato de crédito e a implantação de critérios rígidos e indiferenciados nas negociações, decisão que contribuiu para generalizar o confronto no setor rural e expandir a anormalidade para o crédito industrial e comercial. A inadimplência, que já era alta, de fato explodiu.

Essa postura mostra como foi entronizada no BB a concepção de que o saneamento patrimonial e financeiro deveria dominar sua hierarquia de prioridades. Na prática, entretanto, o programa de ajuste não obedeceu a um planejamento definido. Ao contrário, foi ganhando forma no processo mesmo de sua execução, pois transitou de um enfoque inicialmente gradualista na administração do que a diretoria do banco chamou de "verdade contábil" para, no momento seguinte, tomar feição de uma ação cirúrgica, tentando concluir o ajuste contábil, financeiro e patrimonial de um único golpe.

Na raiz de cada fase do ajuste, abrigada pela posição das autoridades econômicas favorável à consolidação de passivos intragoverno, encontrava-se o que se poderia chamar de "vocação empresarial" da nova diretoria, manifesta na tentativa de impedir que o Banco do Brasil reassumisse o papel de reciclador das dívidas dos setores fragilizados. Fracassada nesse intento, sua lógica levoua a objetivar o repasse do ônus ao controlador, o Tesouro, transformando-a paradoxalmente em aliada objetiva da bancada rural, apenas zelando para que os acordos em discussão não punissem o agente financeiro. Assim, o racionamento de crédito do $\mathrm{BB}$ na verdade abriu caminho para seu oposto, isto é, a vitória quase total do setor privado, que conquistou progressivamente uma ampla reciclagem de suas dívidas - com o detalhe de que coube ao Tesouro Nacional assumir diretamente um ônus ampliado. Os detalhes a seguir informam e 
desdobram essa afirmação.

Os "mega-prejuízos" de 1995 e 1996, somando quase 12 bilhões de reais, deveram-se em boa parte ao erro de cálculo da diretoria, que subestimou a situação real da agricultura e, mais ainda, o entorno político da empresa. Isso implica que o argumento oficial de que os resultados negativos desses exercícios deveram-se ao relacionamento anterior entre o BB e o Tesouro não é consistente. Ao contrário, o conjunto de serviços e operações que o BB executou por conta do governo e que até então não haviam sido ressarcidos na verdade contribuíram positivamente, quando de seu reconhecimento em 1995, para o resultado do banco. Como foram gerados antes dessa data, prejudicaram de fato as administrações anteriores, mas nesse ano permitiram à gestão Ximenez expressiva apropriação de receitas.

Além disso, seria possível à empresa, administrando sua relação com a clientela e definindo seu enfoque contábil, alcançar resultados menos negativos que os apresentados e diminuir os impactos fiscais associados a sua cobertura. Note-se que o resultado do BB em 1995 e 96 gravita ao redor da gestão do crédito: a inadimplência provocou um impacto total negativo de $\mathrm{R} \$ 8,1$ bilhões, enquanto o efeito negativo da valorização do real foi de $\mathrm{R} \$ 1,3$ bilhão.

Foi decisivo, para tanto, que essa inadimplência excedesse em muito a faixa dos "contumazes". Embora os grandes devedores respondessem pela maior parcela da dívida, o alastramento da anormalidade forneceu à representação parlamentar do setor a legitimidade suficiente para uma barganha desimpedida de seu apoio às reformas constitucionais. Isso frustrou a tática inicial do banco de focalizar a pressão sobre os maiores devedores, pois além do peso de sua representação no Congresso Nacional, eles romperam seu isolamento social. Nessas circunstâncias específicas, a alternativa viável teria sido acomodar parcialmente as demandas setoriais através de um processo seletivo de renegociações - aceitando, desde logo, um teto socialmente defensável para a reciclagem das dívidas que minimizasse seu montante global e ao mesmo tempo abrangesse o mais amplo conjunto de contratos de pequeno e médio valor.

Sem oferecer concessões para deter o contágio da reação política a sua nova postura, o ritmo de implementação da "verdade contábil" escapou ao controle da direção do BB, fechando o horizonte para uma estratégia gradualista. Sua conversão à terapia de choque evidencia-se primeiro no fato dela haver rechaçado, em 1995, uma proposta inicial de capitalização, por considerá-la desnecessária. No ano seguinte, a adesão materializou-se na adoção de critérios mais conservadores para enquadramento dos créditos em situação irregular, bem como na opção de lançar de uma única vez o efeito restante da valorização 
cambial de 1994 ao invés de continuar a fazê-lo em parcelas semestrais, contribuindo assim para gerar, no primeiro semestre de 1996, o mega-prejuízo de R \$ 7,5 bilhões.

Como conseqüência do fracasso da estratégia gradualista e sua subseqüente reorientação, o tamanho da capitalização necessária para o reequilíbrio patrimonial do banco e o respectivo custo fiscal do processo foram ampliados. Diante disso, merece ser apontada a hipótese de que a causalidade prejuízo-capitalização não tenha sido exclusivamente unidirecional. A própria disposição do Tesouro para "cobrir o rombo", isto é, proceder ao saneamento patrimonial da instituição com recursos orçamentários, teria viabilizado a magnificação dos prejuízos compondo um episódio de moral hazard algo singular. Os prejuízos que a instituição financeira esperava acomodar associavamse não à ineficiência na concessão do crédito, mas sim à incapacidade para implementar uma estratégia eficaz de cobrança; singular também porque a acomodação se apoiou não na expectativa de auxílio pelo liquidez do Bacen, como emprestador de última instância, mas no aporte de capital doTesouro Nacional enquanto controlador.

Segundo a lógica inerente à dimensão privada da instituição e à vocação empresarial de sua diretoria também seria racional aproveitar essa predisposição do controlador em tirar mais um "esqueleto do armário", pois quanto maior o aporte maior a garantia de que a reversão das reservas viesse a contribuir com resultados positivos ao longo dos exercícios seguintes. O que aliás ocorreu, prestando-se a corroborar o caráter exitoso do programa de ajuste na versão oficial.

A questão de fundo envolvendo a reestruturação do Banco do Brasil em seus aspectos patrimonial, operacional e administrativo diz respeito ao tipo de horizonte que o processo elegeu em diferentes momentos - se voltado prioritariamente para o fortalecimento da instituição enquanto instrumento de políticas de governo ou para uma retirada do Estado daqueles papéis que envolviam o BB, alinhando-o no marco da política de desestatização dos bancos públicos que ganhava impulso naquele contexto.

Uma das componentes mais visíveis do programa de reestruturação foi a segmentação administrativa/operacional segundo as atividades do banco em Unidades Estratégicas de Negócio, que perpassaram as empresas do conglomerado, e Unidades de Função, fornecedoras de insumos àquelas. Traçando cortes longitudinais na organização, o programa procurou dar a cada uma o estatuto de "empresa dentro da empresa". A perspectiva era de que essas unidades se tornassem independentes a ponto até de consagrar uma ênfase comercial em suas inter-relações; o caráter de tal medida excedia portanto os propósitos 
de segmentação contábil preconizados pelo governo (MINISTÉRIO DA FAZENDA, 1995b), que focalizam a transparência das operações para evitar o subsídio cruzado dentro dos bancos federais, isto é, que os lucros do segmento comercial subsidiem as atividades de cunho social.

A esta altura, é oportuno costurar algumas conclusões intermediárias e ressaltar a dupla leitura que cada etapa desse processo comporta. A lógica subjacente à reestruturação baseada em "unidades independentes", se por um lado orientava a meta autojustificável de aprofundar a racionalidade administrativa, poderia simultaneamente atender ao propósito de preparar o conglomerado para um processo de privatização "fatiado", no qual as unidades ou ativos mais rentáveis seriam tangidos para leilões específicos, reproduzindo andamento análogo ao do programa de privatização brasileiro. A tentativa de privatização de sua mais importante subsidiária, já mencionada, apontava justamente nesse sentido.

Entretanto, o encaminhamento desse programa de reestruturação tropeçou nas conseqüências mal calculadas da implantação do novo paradigma na gestão de crédito, conforme visto há pouco. Com isso, o descontrole na implementação da "verdade contábil" levou ao abandono do gradualismo do processo de ajuste. A mudança de rota materializou-se na decisão de lançar todo o impacto da inadimplência e da variação cambial de uma única vez, amplificando o prejuízo do exercício do primeiro semestre de 1996.

Aqui novamente cabe uma dupla leitura, ou melhor, a identificação de como duas motivações distintas podem ter se solidarizado operando em seus respectivos espaços. Se o impacto viesse a ser assumido pelo Tesouro, o balanço do banco seria limpo e, com provisões volumosas, ele estaria apto a voltar à rota de resultados positivos em futuro próximo. Ao mesmo tempo, enquanto prejuízos menores não garantissem tal efeito, a geração de um mega-prejuízo contribuiria para precipitar um ambiente onde a privatização do BB talvez se viabilizasse como solução derradeira para os custos que o Estado incorre ao controlar essa instituição. De toda forma, ainda que a estratégia do banco abrisse horizontes alternativos para o enfrentamento da situação que ela mesmo gerou, sua capitalização, baseada em aportes do Tesouro, representou um retrocesso no eventual projeto privatizante.

A hipótese anterior sustenta-se pela coerência com que articula o conjunto de evidências já examinadas além de outras menos relevantes, que podem ser indicadas. Em novembro de 1995, quando se configurou o desastre provocado pela condução inepta da "mudança de paradigma" no tratamento de sua clientela histórica, o presidente do banco anunciou, na Comissão de Assuntos Econômicos do Congresso Nacional, que a instituição levaria a leilão público, 
com deságio, créditos entre $\mathrm{R} \$ 3,7$ bilhões e 7,1 bilhões ( $O$ Estado de São Paulo, 13 set. 1995). Embora tais leilões tenham ocorrido muito tempo depois e em proporções muito reduzidas, deixa entrever que a via de solução vislumbrada pela direção do banco era a de privatizar ativos, fossem créditos securitizados, fossem participações acionárias, como foi tentado com a BBDTVM e a BB-Securities, em 1998. Um registro que merece menção ainda que rápida é a visita feita ao Brasil, em janeiro de 1996, por uma missão composta de diretores do banco Crèdit Lyonnais, para reuniões com o governo e a direção do $\mathrm{BB}$, conforme a imprensa noticiou à época; recorde-se a propósito que o governo da França já encaminhava então o processo de privatização daquele seu banco.

Consumado o prejuízo, a medida fundamental de recuperação do banco foi sua recapitalização via emissão de novas ações, no montante de R 8 bilhões. O programa previa inicialmente que, além de recursos do Tesouro, uma parcela da oferta pública de ações da ordem de R \$1,2 bilhão seria subscrita por investidores privados, enquanto o restante seria adquirido por agentes estatais e para-estatais, como o fundo de previdência do funcionalismo do BB (PREVI) e o BNDESPAR. Seu lançamento deu-se de forma algo contraditória e os resultados se revelaram distantes dos que o governo esperava. Quando o Ministro da Fazenda anunciou que o Tesouro concorreria com um aporte entre $\mathrm{R} \$ 2,0$ e 2,5 bilhões, o prejuízo total de 1995 ainda não havia sido divulgado, embora sua grandeza já fosse esperada. Mas pouco depois, ao antecipar que o resultado negativo do primeiro semestre de 1996 iria consumir isoladamente quase três quartos dos valores totais envolvidos na capitalização, o presidente do BB acabou soterrando a intenção de atrair maior participação privada no capital do banco. O valor de mercado das ações caiu em torno de $30 \%$, permanecendo por muitos meses abaixo do preço que o banco estipulou para os novos papéis.

Os investidores não assimilaram a relação entre dividendos esperados e valor patrimonial e ausentaram-se do processo. Dois meses depois da oferta inicial, apenas R \$ 20 milhões foram colocados junto ao público, não obstante a inclusão de facilidades adicionais como o bônus de subscrição e o crédito oferecido pela BB-Financeira. Com isso, restou ao próprio Tesouro Nacional destinar $\mathrm{R} \$ 6,4$ bilhões à capitalização do $\mathrm{BB}$ - sendo a maior parcela em títulos e o restante em ações de estatais, obtendo em contrapartida ações do BB -, enquanto a PREVI entrou com pouco mais de R $\$ 1$ bilhão e o BNDESPAR com meio bilhão.

Em que pese ter significado uma "estatização" maior do Banco do Brasil pelo ângulo de sua composição acionária, a capitalização não deteve por muito tempo a retomada da lógica privatizante que sua reestruturação abrigava. 
Em 1998, a direção do conglomerado ainda tentou sem sucesso alienar o controle majoritário da BB-DTVM e da BB-Securities, como foi visto. A mais recente iniciativa do governo na área dos bancos públicos iniciou-se em 1999, quando o governo retomou o debate sobre a reestruturação das instituições financeiras federais em seu conjunto a partir de um projeto contratado junto a uma consultoria privada; suas conclusões e propostas seriam inicialmente debatidas no Congresso Nacional ao longo do ano 2000.

\section{CONCluSÃo}

Para analisar a forma concreta de como a contradição entre a dimensão pública e a face empresarial marca a dinâmica de expansão e diversificação do Banco do Brasil no período pós-1986, este artigo deteve-se na inserção dessa estatal financeira no quadro das finanças públicas e seu papel na atividade de fomento creditício ao setor rural. Além desses aspectos, a formação, desempenho e reestruturação patrimonial do conglomerado financeiro também estiveram em foco.

Assim, entre as políticas para as quais o BB tem sido instrumental não foi objeto de um exame mais detalhado sua atuação na área internacional, que envolveu o processo de endividamento externo e o comércio exterior brasileiro, nem tampouco a relação com a reestruturação mais recente das finanças públicas, onde se incluem questões como a do carregamento dos "precatórios" emitidos pela cidade de São Paulo. Também não se tratou neste artigo do papel do banco no processo de descentralização administrativo no setor social, como operador do Fundef (Fundo de Manutenção e Desenvolvimento do Ensino Fundamental e Valorização do Magistério) e dos fundos estaduais e municipais de saúde (abrangendo em conjunto recursos da ordem de $\mathrm{R} \$ 20$ bilhões/ano), entre outros assuntos. A hipótese aqui foi que a abertura do panorama de investigação para esses temas não alteraria, ou viria mesmo reforçar a substância das conclusões apresentadas a seguir.

Após 1986, a lógica expansiva do Banco do Brasil permaneceu diferenciada da que preside o comportamento dos agentes financeiros privados, cuja racionalidade prioriza um approach seletivo da liquidez, risco e rentabilidade. Enquanto agente estatal, continuou sobrepondo a tal percepção a orientação "pública" das Autoridades Econômicas, voltada para a sustentação da renda e condições de operação de uma gama de atividades privadas não-financeiras. Fundamentalmente, o BB preservou sua posição central no Sistema Nacional de Crédito Rural, mas com modificações drásticas nas condições em que 
desempenha esse papel, passando a apoiar-se antes de tudo em recursos mobilizados concorrencialmente nos mercados financeiros.

Essa inconsistência - operações ativas sob forte influência da política econômica e operações passivas sujeitas a condições de mercado - encontra-se na raiz da crise que se verificou em sua dimensão empresarial, na sua constituição de grande empresa sujeita a critérios de valorização privada. Nos anos oitenta e noventa, a resposta às condições macroeconômicas e à crise físcal e financeira do setor público no sentido do aprofundamento e diversificação do BB nos mercados financeiros visou compatibilizar as determinações de caráter público e empresarial de sua dinâmica expansiva. Esse movimento obedeceu não apenas à necessidade de superar a fragilização patrimonial e financeira da instituição após as reformas de 1986-88, senão para, ao fazê-lo, atender a imperativos de política econômica, o que significou subordinar-se à "valorização do capital como um todo" sustentando a rentabilidade das atividades econômicas privadas, no sentido apontado na Introdução.

Daí que o propósito de imprimir um caráter eminentemente privado à gestão dessa empresa estatal acabou encontrando certos limites estruturais, realçados pela instabilidade conjuntural interna e externa. Ou seja, a mesma ordem de determinações que presidiu o processo de expansão do conglomerado também restringiu o horizonte para seu desdobramento. O propósito de implantar uma reestruturação que preparasse o banco para a privatização chocou-se com a inadimplência e os prejuízos, a tentativa de manter a participação privada no capital fracassou no mercado interno e não sensibilizou investidores internacionais, e o esforço para privatizar uma das mais importantes empresas do conglomerado não encontrou mercado devido à retração dos fluxos internacionais de capitais e às divergências na própria base de sustentação do governo.

Nessa perspectiva de análise, a capitalização de R 8 bilhões do Banco do Brasil adquire um sentido mais preciso. Ela constituiu o ápice de sucessivos movimentos que acompanharam o fim dos créditos largamente subsidiados à agricultura, após a extinção da conta-movimento em 1986, período em que a proteção creditícia do Estado à agricultura não desapareceu, mas ficou camuflada na crescente deterioração das contas do BB. Enfrentada a crise com a reestruturação patrimonial da estatal financeira, foi como se a capitalização viesse a posteriori preencher a função da conta-movimento. Com a diferença de que, embora a natureza fiscal de tais recursos estivesse mais bem explicitada, a definição das condições financeiras e dos montantes envolvidos permaneceu sujeita a processos incertos e precários. 


\title{
RESUMO
}

Este artigo aborda a empresa estatal financeira Banco do Brasil S.A., no período de 1986/88 a 1996/98, com o objetivo de analisar como foi tratada por sucessivos governos a crise decorrente da inconsistência entre seu papel "público" - particularmente o fomento creditício ao setor rural - e sua dimensão de grande empresa inserida concorrencialmente nos mercados financeiros. Examinando os momentos que marcaram a trajetória da estatal, mostra-se como a predominância de seu caráter público impôs limites estruturais à implantação de uma racionalidade privada no encaminhamento de suas estratégias.

\begin{abstract}
This article focuses on the state-owned financial institution Banco do Brasil S.A., over the period from 1986/88 to $1996 / 98$, with the purpose of analyzing how it was addressed by successive governments the crisis that arose from the inconsistency between its "public" role - particularly as a subsidized credit supplier to the rural sector - and its competitive behavior as a large financial conglomerate. Examining the moments that marked the path of the state-owned company, it is shown that the predominance of BB's public character has imposed structural limits to establishing a "private rationality" in its strategic management.
\end{abstract}

\section{REFERÊNCIAS}

BANCO CENTRAL DO BRASIL. Anuário Estatístico do Crédito Rural, Brasília, vários números.

BANCO DO BRASIL S.A. Demonstrativos Contábeis, Brasília, 1985-1998. Relatórios Anuais 1985-1998. Brasília.

BANCO DO BRASIL E MINISTÉRIO DA FAZENDA. Pendências entre o Banco do Brasil e o Tesouro Nacional. Relatórios Finais dos GT's, constituídos pela Portaria MF 150, de 26.04.1995. Brasília, 1995.

BANCO DO BRASIL, BANCO CENTRAL E MINISTÉRIO DA FAZENDA. Relações institucionais entre o Tesouro Nacional, o Banco Central e o Banco do Brasil. Relatório Final do GT-3, referente ao voto CMN 283, de 21.08.84. Brasília, 1984.

CARVALHO, C. E.; PINHEIRO, M. M. S. FGTS: avaliação das propostas de reforma e extinção. Brasilia: IPEA, 1999. 41 p. (Texto para Discussão, 671). 
VIDOTTO, C. A. Crise e reestruturação de uma estatal...

CESARE, Claudia F. de. Produtores atrasam o pagamento da dívida securitizada. Gazeta Mercantil, São Paulo, 12 Jan. 1999.

CRUZ, Paulo R. C. D. Dívida externa e política econômica. A experiência brasileira nos anos setenta. São Paulo: Brasiliense, 1984.

FUNDAP. Sistema bancário público e privado. Mudança na estrutura de recursos e tendências de custo e lucro (1985/87). São Paulo: IESP/FUNDAP, 1988. (Textos para Discussão, 13).

GUARDIA, Eduardo R. O processo orçamentário do Governo Federal: considerações sobre o novo arcabouço institucional e a experiência recente. São Paulo: IESP/FUNDAP, 1993. (Textos para Discussão, 12).

MINISTÉRIO DA FAZENDA. Renegociação das dívidas dos agricultores. Brasília: Secretaria de Política Econômica, 1995a. Página do Ministério da Fazenda na Internet (www.fazenda.gov.br). Atualmente não está mais disponível na página.

MINISTÉRIO DA FAZENDA. Nota Técnica 020/95. Brasília: Secretaria Executiva do Ministério da Fazenda, 1995b.

PINHEIRO, M. M. S. O papel dos fundos parafiscais no fomento: FGTS e FAT. Brasília: IPEA, 1997. (Texto Para Discussão, 485).

STENZEL, Raquel. BB quer fazer leilão de créditos. O Estado de São Paulo, 13 set. 1995.

TAVARES, Maria da Conceição. O rombo do Banco do Brasil. Correio Brasiliense, 14 abr. 1996.

TRIBUNAL DE CONTAS DA UNIÃO. Relatório de inspeção extraordinária. Diretoria da Área Internacional do Banco do Brasil S.A. Voto do relator Min. Homero Santos. Brasília, 1992.

VIANNA, Maria L. T. W. A administração do "Milagre". O Conselho Monetário Nacional 1964-1974. Petrópolis: Vozes, 1987.

VIDOTTO, Carlos A. Banco do Brasil. Crise de uma empresa estatal do Setor Financeiro (196492). Campinas, 1995. Dissertação (Mestrado) - IE Unicamp.

Dimensão pública e privada de uma estatal financeira: o Banco do Brasil no auge e declínio cíclicos. Revista da Sociedade Brasileira de Economia Política, Rio de Janeiro, n. 1, p. 159-187, 1997. 